\title{
Análise de políticas públicas para bibliotecas no Brasil
}

Analysis of public policies for libraries in Brazil

\author{
Elisa Campos Machado \\ Doutora em Ciência da Informação pela ECA/USP. \\ Profa. Dra. do Departamento de Estudos e Processos Biblioteconômicos, do Centro de Ciências Humanas \\ e Sociais/UNIRIO. \\ E-mail: emachado2005@gmail.com
}

\section{Resumo}

Aborda a necessidade de desenvolvimento de análises de políticas públicas para as bibliotecas no Brasil, com o objetivo de contribuir para alterar a realidade evidenciada no primeiro Censo Nacional de Bibliotecas Públicas Municipais. A partir de um panorama das políticas públicas para a área, nas três esferas da federação, é possível identificar mudanças positivas no âmbito federal, que, no entanto, não se apresentam como garantias de mudanças efetivas da realidade nacional. No âmbito estadual e municipal, a situação é mais grave, tendo em vista a falta de consciência dos governos locais em destinar esforços para a construção de políticas públicas para essa área. Nesse contexto, defende a necessidade de aprofundar os estudos e lançar mão de metodologias que ajudem a explicar as causas e consequências de determinadas ações governamentais.

Palavras-chave: Biblioteca Pública. Políticas Públicas para Bibliotecas. Brasil.

\begin{abstract}
The paper focuses the need to develop public policies for libraries in Brazil in order to change the reality shown by the 1st National Census of Municipal Public Libraries. Considering the panorama of public policies for the area, we conclude that despite the positive changes on the federal government, there is little on the overall national reality. The state and municipal governments are not aware of the importance to gather efforts to built public policies. On this context, it emphasizes the necessity to develop a studies and methodologies to explain the causes and consequences of governmental actions.
\end{abstract}

Keywords: Public Library. Public Polices for Libraries. Brazil

\section{Introdução}

Hoje vivendo na chamada sociedade da informação e do conhecimento, e com as novas tecnologias a nosso favor, a biblioteca pública, aquela criada e mantida pelo Estado, deveria ser o ponto de apoio local para a sociedade ter acesso à informação e à leitura. No entanto, no Brasil, essas bibliotecas, de modo geral, ainda são entendidas pela população como um espaço unicamente físico, de organização de documentos no suporte papel e que têm como atividade principal o atendimento às pesquisas escolares.

O discurso político sempre defendeu e ressaltou a importância das bibliotecas públicas, mas na prática pouco foi feito para apoiar efetivamente estas instituições. A 
herança histórica brasileira de desigualdades favoreceu o processo de desmonte do Estado, do serviço público e das instituições ligadas a ele, tais como as bibliotecas públicas. Em relação às políticas públicas, os governos, por décadas seguidas, tomaram decisões com base em um viés conservador e elitista, o que levou à uniformização de propostas, as quais eram enquadradas em formatos genéricos que facilitavam o tratamento administrativo (COSTA; DAGNINO, 2008).

O impacto de políticas de estilo uniformizador, centralizador e tecnocrático para bibliotecas foi evidenciado no primeiro Censo Nacional de Bibliotecas Públicas Municipais, realizado no período de setembro a novembro de 2009 e publicado em 2010. Em sua maioria, as bibliotecas públicas brasileiras não possuem recursos suficientes para se manter, para atualizar seus acervos, investir em tecnologia e muito menos na formação e qualificação de suas equipes, prescindindo muitas vezes do próprio profissional formado.

É importante lembrar que o Brasil sempre teve uma grande dificuldade em coletar, organizar e sistematizar informações sobre suas ações, acervos e equipamentos culturais. Esse fato é apontado pela UNESCO (2006) em seu texto sobre as estratégias de atuação no Brasil, onde afirma que pouco se fez para avaliar o verdadeiro valor da cultura no país. Portanto, a realização desse censo por si só já é um avanço. Afinal, como construir políticas públicas de qualidade se não temos um diagnóstico da nossa realidade?

Nesse sentido, nos últimos anos, algumas ações foram implementadas pelo Ministério da Cultura (Minc) para suprir o déficit de informação organizada na área da Cultura. Em 2004 foi firmado um convênio com o Instituto Brasileiro de Geografia e Estatística (IBGE), com o objetivo de criar o Sistema de Informação e Indicadores Culturais (Sniic), que apresenta como um dos resultados o Suplemento de Cultura da Pesquisa de Informações Básicas Municipais (MUNIC 2006) ${ }^{1}$ e, em 2009, foi publicado o anuário de estatísticas culturais - Cultura em números, resultado da compilação de dados levantados em pesquisas desenvolvidas em parceria com o IBGE, o Instituto de Pesquisas Econômicas e Aplicadas (IPEA) e outras fontes.

\footnotetext{
${ }^{1}<$ http://www.ibge.gov.br/home/estatistica/economia/perfilmunic/cultura2006/>
} 
Especificamente no que se refere às informações sobre bibliotecas, até há bem pouco tempo só contávamos com o cadastro $^{2}$ do Sistema Nacional de Bibliotecas Públicas (SNBP) o qual disponibiliza a relação de bibliotecas públicas conveniadas ao órgão. Em 2003, o MinC deu início à constituição de um banco de experiências ${ }^{3}$ com vistas a mapear as ações em prol do livro e da leitura e, em 2010, a Fundação Getúlio Vargas (FGV) apresentou o primeiro Censo Nacional das Bibliotecas Públicas Municipais, que teve como objetivo principal realizar um mapeamento e um levantamento sobre as condições de funcionamento desses equipamentos.

Com base nesse contexto, consideramos importante reforçar a discussão sobre a necessidade de desenvolvermos análises de políticas públicas para bibliotecas. A análise de uma política, segundo Dye (1976, apud COSTA; DAGNINO, 2008, p. 23) “é descobrir o que os governos fazem, por que fazem e que diferença isto faz". Implica em: “identificar as organizações (instituições públicas) com elas envolvidas e os atores que nestas se encontram em posição de maior evidência", identificando suas relações institucionais; "pesquisar as relações que se estabelecem entre esses atores-chave que representam os grupos de interesses existentes no interior de uma instituição e de grupos externos" e, por fim, comparar sistematicamente a situação observada com o padrão proposto, ou seja, a estrutura de poder e das regras de sua formação (COSTA; DAGNINO, 2008, p.100).

Paiva (2008) apresentou uma análise consistente sobre o assunto em sua dissertação de mestrado, no entanto, a literatura, em sua maioria, discute as políticas para o livro e a leitura (LINDOSO, 2004; ROSA E ODDONE, 2006). Nesse trabalho, optamos por focar a atenção nas políticas específicas para bibliotecas públicas com o objetivo de contribuir para ampliar o repertório para o desenvolvimento de análises de políticas especificamente para este tipo de instituição. Nesse sentido, apresentamos a seguir um panorama, das duas últimas décadas, das políticas públicas para bibliotecas, nas três esferas da Federação.

\footnotetext{
${ }^{2}<$ Endereço eletrônico: http://catalogos.bn.br/scripts/odwp012k.dll?INDEXLIST=snbp_pr:snbp>

${ }^{3}<$ Endereço eletrônico: http://www.pnll.gov.br/>
} 


\section{Políticas culturais e as bibliotecas}

A sociedade em geral costuma relacionar as bibliotecas públicas à área de Educação. No entanto, elas estão inseridas institucionalmente na área de Cultura. Portanto, são as políticas culturais que, por meio de sua administração pública e do conjunto de leis e regulamentações, buscam caminhos para o fortalecimento dessas bibliotecas e o estabelecimento de ações de longo alcance, com caráter permanente.

Acreditamos que a relação estabelecida entre a biblioteca pública e a área da Educação se dá no Brasil por três motivos: primeiro, pelo forte caráter educacional que essa biblioteca desempenha, principalmente em decorrência do que consideramos ser o segundo motivo; a carência de bibliotecas escolares no país ${ }^{4}$; e, terceiro, pelo fato da cultura ser a base de toda a sociedade e suas ações terem por princípio a transversalidade e a multiplicidade. Nesse sentido, pensar a cultura e políticas públicas culturais é reconhecer a complexidade que envolve vários elementos, esferas, níveis e atores, ou seja, como afirma Morin (2002, p. 38), confrontamo-nos "cada vez mais e de maneira cada vez mais inelutável com os desafios da complexidade".

A cultura como direito de todos está inscrita na Declaração Universal dos Direitos Humanos e, no Brasil, é reafirmada na Constituição de 1988, no artigo 215: “O Estado garantirá a todos o pleno exercício dos direitos culturais e acesso às fontes da cultura nacional, e apoiará e incentivará a valorização e a difusão das manifestações culturais". No entanto, é por meio das políticas públicas que garantiremos a cultura como direito de todos.

As políticas públicas culturais, especificamente, envolvem um conjunto de iniciativas que tem por objetivo "promover a produção, a distribuição e o uso da cultura, a preservação e divulgação do patrimônio histórico e o ordenamento do aparelho burocrático por elas responsável" (COELHO, 2004, p. 293). Essas iniciativas se apresentam na forma institucionalizada como leis, decretos, programas e projetos e na forma de ações propositivas.

Os estudos sobre os processos de elaboração de políticas públicas costumam ser divididos em 3 fases sucessivas: formulação, implementação e avaliação. A fase de

\footnotetext{
${ }^{4}$ Em maio de 2010 foi aprovada a lei 12.444/2010 determinando que todas as escolas brasileiras tenham uma biblioteca escolar.
}

InCID: R. Ci. Inf. e Doc., Ribeirão Preto, v. 1, n.1, p. 94-111, 2010. 
formulação pode ser participativa ou autoritária, dependendo do âmbito do processo decisório em que é concebida. A implementação é feita mediante os órgãos e mecanismos existentes ou criados na administração para esse fim. E a avaliação, por sua vez, é feita a partir da comparação entre o que foi planejado e os resultados e impactos decorrentes da implantação da política em questão (COSTA; DAGNINO, 2008).

É no momento de formulação que se estabelece a forma de participação. Quanto mais participativo, menos racional é o processo, e quanto mais desequilibrada for a correlação de forças entre os atores, menor será a possibilidade de implementar uma política pública formulada de maneira participativa. Nesse sentido, Costa e Dagnino (2008, p. 135) alertam para o fato de estarmos num país em "que as políticas são geradas e implantadas em um ambiente marcado por uma grande desigualdade de poder, de capacidade de influência e de controle de recursos entre os diversos atores sociais".

Segundo Calabre (2007, p. 1), “a institucionalização da política cultural é uma característica dos tempos atuais". No Brasil, segundo a autora, foi no governo de Getúlio Vargas (1930-1945) que foram implantadas o que se pode chamar de primeiras políticas culturais, naquele momento com o objetivo de institucionalizar o setor cultural. No entanto, podemos considerar que somente a partir de 2003 é que o Estado passou a dialogar com seus interlocutores e assim identificar e valorizar manifestações até então ignoradas. A partir desse momento ampliaram-se os debates e as possibilidades de participação da sociedade na construção de políticas públicas para a área, redefinindo assim os rumos em relação à gestão pública de cultura. Nesse contexto, em 2005 foi criado o Sistema Federal de Cultura ${ }^{5}$, com o objetivo de integrar os órgãos, programas e ações do governo federal e, pela primeira vez na história, temos uma Proposta de Plano Nacional de Cultura ${ }^{6}$, que se constitui em um plano de estratégias e diretrizes para a execução de políticas públicas para os próximos 10 anos.

É evidente que houve uma mudança significativa no nível federal. No entanto, localmente a cultura continua sendo uma área pouco valorizada. Segundo o MUNIC2006, 57,9\% dos municípios brasileiros afirmam executar algum tipo de política de cultura, apenas $6,8 \%$ conta com uma secretaria ou fundação pública exclusiva para a área e somente $17 \%$ conta com o Conselho Municipal de Cultura.

\footnotetext{
${ }^{5}$ Decreto 5.520, de 24 de agosto de 2005.

${ }^{6}$ Projeto de Lei ${ }^{\circ} 6.835 / 2006$
}

InCID: R. Ci. Inf. e Doc., Ribeirão Preto, v. 1, n.1, p. 94-111, 2010. 
Dando continuidade ao processo de articulação e estabelecimento de políticas públicas, o governo federal lançou, em outubro de 2007, o Programa Mais Cultura ${ }^{7}$, que, com a previsão de investir $\mathrm{R} \$ 4,7$ bilhões na área até 2010 , tem como proposta agir de forma ampla, contundente e transversal no mapa das prioridades que, no que se refere à Cultura, o momento atual impõe para a sociedade.

Historicamente, o Ministério da Cultura se apresenta como uma instituição pobre, com parcos recursos e uma diminuta estrutura organizacional, incompatível com as demandas atuais e de um país permeado pela diversidade como é o Brasil. Segundo Medeiros $(2008)^{8}$, o Ministério conta com apenas 0,6\% do Orçamento da União, sendo que a ONU recomenda 1\%. Essa condição justificou, na década de 1980, a criação de leis de renúncia fiscal, transferindo para a iniciativa privada o poder de definir os investimentos na área.

\section{Políticas Públicas Nacionais para Bibliotecas}

Segundo Lindoso (2004) "a percepção da importância das bibliotecas não surge espontaneamente na população. É um trabalho de décadas de conscientização e de investimento público [...]". Se nos basearmos na análise realizada por Paiva (2008) é possível perceber que, nas últimas décadas, as políticas públicas para bibliotecas no Brasil pouco contribuíram para melhorar essa percepção.

Desde a criação do INL, em 1937, os governos se esforçavam na criação de bibliotecas públicas, criadas como ações governamentais sem a participação da sociedade. Somente a partir de 2003 percebemos algumas mudanças no sentido de ampliar o diálogo e a participação da sociedade.

Apesar de nem sempre terem obtido sucesso e, em alguns casos, não estarem articuladas de maneira a serem potencializadas, algumas ações do Estado anteriores a 2003 merecem atenção.

\footnotetext{
${ }^{7}$ Decreto ${ }^{\circ} 6.226$, de 4 de outubro de 2007.

${ }^{8}$ A Proposta de Emenda à Constituição (PEC) 150, de 2003, está em tramitação no Congresso Nacional e vincula para a Cultura $2 \%$ do Orçamento da União, $1,5 \%$ dos estados e $1 \%$ dos municípios.
}

InCID: R. Ci. Inf. e Doc., Ribeirão Preto, v. 1, n.1, p. 94-111, 2010. 
Em 1992, no âmbito Federal, vinculado ao Ministério da Cultura, foi criado o Sistema Nacional de Bibliotecas Públicas (SNBP) com o principal objetivo de fortalecimento das bibliotecas públicas por meio da "implantação de um processo sistêmico baseado em ações voltadas para a interação e integração dessas bibliotecas em âmbito nacional" (BIBLIOTECA NACIONAL, 2006). Para tanto, criou-se em cada estado brasileiro um Sistema Estadual de Bibliotecas Públicas, o qual, por sua vez, tem por meta articular as ações das diversas Bibliotecas Públicas Municipais. Atualmente, é de responsabilidade do SNBP o desenvolvimento das seguintes ações: programa Livro Aberto, que propõe implantar bibliotecas em municípios que não as possuem e a revitalizar as já existentes; cadastro de bibliotecas públicas; capacitação e seminários; e assessoria técnica para as bibliotecas que fazem parte do sistema.

A nosso ver, a concepção do SNBP foi inovadora, no sentido de propor um sistema que pudesse agir de forma ramificada nesse país de dimensões continentais, porém, sua subordinação à Fundação Biblioteca Nacional (FBN) amarrou sua estrutura, eliminando a possibilidade de agir de maneira autônoma e, consequentemente, minando sua capacidade e força para atuar efetivamente e de maneira contínua na dinamização e no fortalecimento das bibliotecas públicas. Esse fato nos faz lembrar o que diz Ladislau Dowbor (1995, p. 4): “o Estado tradicional faz figura de dinossauro, amplamente ultrapassado por uma dinâmica que exige respostas rápidas e flexíveis a situações diversificadas e complexas".

Em 1993 surge o programa Uma Biblioteca em Cada Município que tinha o objetivo de implantar bibliotecas pelo país. O compromisso era de distribuir estantes, livros e oferecer capacitação para o gerenciamento dessas bibliotecas. Um típico exemplo de política elaborada no estilo tradicional, ou seja, universalista, centralizada e tecnocrática.

Ainda em 1992, o governo federal lança o Programa Nacional de Incentivo à Leitura (PROLER), também vinculado à FBN. O PROLER, por meio de seus comitês regionais, desenvolve ações em parceria com as secretarias estaduais e municipais de cultura e educação pelo país. Em sua sede, no Rio de Janeiro, denominada como Casa da Leitura, são oferecidos cursos de formação, palestra, entre outras atividades de incentivo à leitura para professores, bibliotecários e agentes de leitura da rede pública. O PROLER surge como uma ação do Ministério da Cultura voltada à formação de 
leitores, nos vários espaços sociais, e ao oferecer formação para bibliotecários de bibliotecas públicas contribuiu indiretamente para apoiar essa instituição.

No que tange ao acesso à informação no mundo digital, o Programa Sociedade da Informação (SOCINFO), lançado em 1996 pelo Ministério da Ciência e Tecnologia, considerou em suas metas as bibliotecas públicas pontos focais naturais para difusão, captação e processamento de conteúdos de interesse público. Dentre as inúmeras ações previstas estava a conexão de todas as bibliotecas públicas do país (TAKAHASI, 2000).

Tendo em vista as precárias condições de comunicação do país em 2000, foi criado o Fundo de Universalização de Serviços de Telecomunicações (FUST), pelo Ministério das Comunicações, com o objetivo de gerar recursos para cobrir os custos da infra-estrutura necessária para a universalização dos serviços de telecomunicações, essenciais para que se pudessem cumprir metas como a de conexão das bibliotecas públicas ${ }^{9}$. No entanto, até hoje nenhum recurso foi destinado a esse fim.

O Ministério da Reforma Agrária, por sua vez, por meio da Secretaria do Desenvolvimento Agrário, lançou em 2003 o projeto Arca das Letras, com o objetivo de criar bibliotecas rurais e formar agentes de leitura locais para atuar nesses espaços. $\mathrm{O}$ projeto prevê o envio de uma caixa-estante, fabricada por sentenciados de penitenciárias estaduais, com uma coleção de 230 livros. Em 2006, criou complementarmente o projeto Bibliotecas Famílias Agrícolas, focando na distribuição de livros para as Escolas Famílias Agrícolas e Casas Familiares Rurais.

Segundo os coordenadores do projeto Arca das Letras, até julho de 2008 foram criadas mais de 6 mil bibliotecas comunitárias em zonas rurais do país, especificamente em assentamentos da reforma agrária, em comunidades de agricultura familiar, comunidades de remanescentes de quilombolas, indígenas, ribeirinhas e em colônias de pescadores (informação verbal) ${ }^{10}$. O projeto inicia o contato com a comunidade por meio das organizações comunitárias locais, tais como sindicatos e movimentos sociais, e prevê em sua metodologia de implantação a participação das comunidades na definição do espaço a ser ocupado pela biblioteca, na formação do acervo, na definição do funcionamento e na sua gestão. Uma ação de incentivo à leitura que vem se

\footnotetext{
${ }^{9}$ Artigo $5^{\circ}$, parágrafos IV, V, VI, VII da Lei $\mathrm{n}^{\circ}$ 9.998, de 17 de agosto de 2000.

${ }^{10}$ Informação fornecida por Cleide Soares, bibliotecária coordenadora do Programa Arca das Letras, durante o II Fórum do Plano Nacional do Livro e Leitura, em agosto de 2008.
}

InCID: R. Ci. Inf. e Doc., Ribeirão Preto, v. 1, n.1, p. 94-111, 2010. 
mostrando importante para as comunidades atendidas, e inovadora na sua concepção, já que trabalha com processos participativos, mas totalmente desvinculada das bibliotecas públicas.

Com esses exemplos, é possível constatar que as ações governamentais voltadas para a área de bibliotecas não se restringem apenas ao MinC, outros órgãos e ministérios incluíram em seus programas ações que, de alguma forma, pretendiam potencializar esses espaços. No entanto, um problema se evidencia: a falta de articulação e sinergia entre as diferentes iniciativas.

É dentro desse princípio que o Programa Fome de Livro, instituído no início de 2005, surge como uma estratégia para articular o conjunto de ações realizadas pelo Estado, pelas empresas e pela sociedade civil organizada. Paralelamente, com o objetivo de iniciar um grande movimento nacional e em sintonia com o Plan Ibero-americano de Lectura, o governo federal estabeleceu o ano de 2005 como o ano do livro e da leitura e instituiu a marca VIVALEITURA. Em decorrência dessa ação surgiu, capitaneada pelo MinC, o Programa Nacional do Livro e da Leitura (PNLL), com a intenção de se constituir numa política de Estado para a área. Segundo Wasserman (2005, apud ROSA; ODDONE 2006, p. 189),

a receptividade do programa aparentemente não convenceu o então presidente da FBN, Pedro Correa do Lago, e o ministro da Cultura, Gilberto Gil, tomou a seguinte medida "[...] tirou a coordenação do Programa Fome do Livro/ Plano Nacional do Livro e da Leitura de sob as asas da Fundação Biblioteca Nacional.

Inicialmente nos parece que essa decisão foi a forma encontrada pelo governo para viabilizar a implementação de um novo processo para a elaboração de políticas públicas para a área de bibliotecas, no entanto, a decisão de desvinculá-lo da FBN gerou a criação de uma nova instância para a elaboração de políticas públicas enfraquecendo, ainda mais, o Sistema Nacional de Bibliotecas Públicas.

Apesar disso, foi a partir desse momento, que se iniciou um processo de articulação dos inúmeros projetos, programas, ações e atividades em geral ligadas ao livro, à leitura, à literatura e à biblioteca. 
Nos objetivos do PNLL podemos constatar a disposição do Estado em reorganizar essa situação, no sentido de articular ações até então dispersas e fragmentadas.

[...] criar condições e apontar diretrizes para a execução de políticas, programas, projetos e ações continuadas por parte de diferentes esferas de governo e também por parte das múltiplas organizações da sociedade civil [...] (PLANO NACIONAL DO LIVRO E DA LEITURA, 2006).

Sem dúvida, não podemos deixar de reconhecer o forte cunho participativo pelo qual o processo foi permeado: foram realizadas inúmeras reuniões regionais e nacionais para discussão e formulação dessa nova política nacional para o livro e a leitura, além das constituições dos representantes e conselhos regionais. Nunca no país tinha ocorrido um processo semelhante.

A proposta foi de reunir governo (federal, estadual e municipal), universidades, professores, bibliotecários, escritores, ONGs e empresas privadas que tivessem envolvimento com o assunto. Para tanto se constituiu a Câmara Setorial do Livro e da Leitura (CSLL) com representantes destes diversos setores.

Abrimos aqui um parêntese para evidenciar o fato de que para nós é significativo que a palavra "livro" seja sempre colocada à frente da palavra "leitura" na concepção desses programas, e mais, da palavra "biblioteca" ser excluída. Entendemos que a valorização do livro como objeto está relacionada à valorização do mercado editorial, que de forma organizada exerce uma forte pressão sobre o Estado: um exemplo da forma inapropriada de participação, que Chauí (2006, p. 146) designa como socialdemocrata e liberal.

Outra questão importante já mencionada e que deve ser analisada é a existência atualmente de dois órgãos reguladores para a área de bibliotecas públicas: o Sistema Nacional de Bibliotecas Públicas e o Plano Nacional do Livro e da Leitura. Segundo Costa e Dagnino (2008, p. 123), é imprescindível que haja uma única agência de implementação de políticas públicas num determinado setor, "que não dependa de outras ou, se outras agências estiverem envolvidas, que as relações de dependência sejam pequenas em número e importância". 
No dia 4 de outubro de 2007, por meio do Decreto Federal n 6.226 , o Presidente da República instituiu o Programa Mais Cultura, com o objetivo de:

\begin{abstract}
I - ampliar o acesso aos bens e serviços culturais e meios necessários para a expressão simbólica, promovendo a autoestima, o sentimento de pertencimento, a cidadania, o protagonismo social e a diversidade cultural; II - qualificar o ambiente social das cidades e do meio rural, ampliando a oferta de equipamentos e dos meios de acesso à produção e à expressão cultural; e

III - gerar oportunidades de trabalho, emprego e renda para trabalhadores, micro, pequenas e médias empresas e empreendimentos da economia solidária do mercado cultural brasileiro. (BRASIL, 2007a, p. 1)
\end{abstract}

O avanço se dá também na criação de uma Câmara Técnica com a tarefa de "articular ações intersetoriais para o desenvolvimento do Programa" com a participação de vários Ministérios, Secretarias, da Casa Civil, assim como de representantes de outras instituições públicas, da sociedade civil e de especialistas. O monitoramento do programa, por sua vez, ficou a cargo do Conselho Nacional de Política Cultural (CNPC) (BRASIL, 2007a).

O Programa Mais Cultura prevê três linhas de ação, sendo que a rede de bibliotecas públicas faz parte da primeira linha, "Cultura e cidadania", que tem por diretriz "garantir o acesso dos brasileiros aos bens e serviços culturais" (BRASIL, 2007b).

Dentro dessa linha de investimento, vários editais foram abertos para que os municípios pudessem pleitear recursos para as bibliotecas públicas do país. O Edital de Concurso Público no 1/2009, "Edital Mais Cultura de Modernização de Bibliotecas Públicas Municipais", por exemplo, destinou um total de 6,5 milhões de reais para a modernização de 200 bibliotecas de municípios brasileiros com até 20 mil habitantes. $\mathrm{O}$ prêmio, neste caso, contemplou investimento em mobiliário, equipamentos e acervo. Mais de 900 propostas foram encaminhadas e, segundo o MinC (BRASIL, 2010), o Estado de Minas Gerais foi o que obteve maior número de municípios classificados, 71, seguido pelo Rio Grande do Sul, com 31, e por São Paulo, com 23.

Atualmente o Edital de Concurso Público no 3/2010, "Edital Mais Cultura de Apoio às Bibliotecas Públicas 2010”, está aberto para inscrições e deve disponibilizar R\$ 30.600.000,00 para investimentos em acervos, equipamentos, mobiliários e 
capacitação de pessoal. Neste caso os investimentos devem atender a três categorias: apoio a Bibliotecas Municipais a partir de melhoria e qualificação dos ambientes físico social e cultural; implantação de bibliotecas de bairro, distritais e/ou rurais; e, apoio às bibliotecas acessíveis.

O Programa Mais Cultura ampliou o conceito dos Pontos de Cultura e criou os Pontos de Leitura, que incorporaram as experiências das bibliotecas comunitárias, ou seja, aqueles espaços de leitura criados por pessoas ou grupos de pessoas, sem vínculo direto com órgãos governamentais, que tem por objetivo ampliar o acesso de uma determinada comunidade à leitura e ao livro. Cabe esclarecer que o Ponto de Cultura é uma ação do Programa Cultura Viva e articula todas as demais ações desse Programa (BRASIL, [2007?]). Ele se realiza por meio do estabelecimento de convênio entre o MinC e lideranças locais responsáveis por iniciativas culturais em comunidades espalhadas por todo o país. Para o MinC, o Ponto de Cultura passa a ser o polo de articulação da cultura local, organizado de maneira a impulsionar as ações que já existem nas comunidades.

O Ponto de Leitura, por sua vez, deve seguir o mesmo princípio, ou seja, ser um polo de articulação local, mas, a nosso ver, diferentemente do Ponto de Cultura este deveria ser articulado às bibliotecas públicas municipais. Dessa forma estaríamos fortalecendo espaços públicos já constituídos, aproximando esferas que têm os mesmos ideais e que, de maneira sistêmica, terão melhores condições de enriquecer seus serviços, assim como sedimentar e multiplicar suas ações.

Ao apoiar as iniciativas locais de forma deslocada das bibliotecas públicas, corremos o risco de mais uma vez fomentar o que Oliveira (1999, p. 57) chama de “desnecessidade do público". Fazendo com que a sociedade assuma, de maneira inadequada, a responsabilidade por serviços públicos que são por essência de responsabilidade do Estado. Para que estes investimentos sejam potencializados é preciso criar sinergia entre os Sistemas de Bibliotecas Públicas e os Pontos de Leitura. 


\section{Políticas Públicas Locais para Bibliotecas}

Quando pensamos na esfera local, estamos nos referindo às políticas públicas criadas para bibliotecas pelos governos municipais e estaduais. Cabe esclarecer que a iniciativa de âmbito municipal, normalmente, tem menor visibilidade e, portanto, são mais difíceis de serem identificadas.

Infelizmente, quando chegamos mais próximos da população, percebemos que os grandes projetos idealizados na esfera federal, na maioria das vezes, não chegam até ela. A maioria dos municípios, tradicionalmente, se comporta como cliente das políticas idealizadas no nível central, e o MinC, por sua vez, por meio de seus projetos de doação de acervos e equipamentos para bibliotecas, estimulou durante anos essa forma de relação. De maneira geral, o MinC sempre exerceu pouca influência sobre os estados e municípios brasileiros. Sem consciência do potencial que têm esses espaços, os governos locais se contentam em receber kits padronizados de bibliotecas, sem nenhuma identificação com as necessidades locais, o que leva à criação de espaços sem atrativos e sem condições de atendimento adequado.

A partir de 2005, a forte divulgação feita pelo VIVALEITURA e o banco de experiências do PNLL, aliados ao momento atual em que a Internet colabora para ampliar o acesso à informação, foram importantes no sentido de dar visibilidade para ações e experiências desenvolvidas no nível municipal e estimular a aproximação entre as esferas.

No Brasil, de modo geral, as bibliotecas públicas são subordinadas às Secretarias de Cultura dos Municípios ou dos Estados, sendo que em alguns municípios as áreas de Cultura e Educação são tratadas de maneira integrada em uma única secretaria Secretaria Municipal de Educação e Cultura.

Segundo Costa e Dagnino (2008, p. 17), as características do estado que herdamos gerou uma situação de conformidade em que

sem nenhuma preocupação com a elaboração de políticas públicas apropriadas, os recursos fluíam através de uma complexa rede de influências e favores até os líderes locais que, discricionariamente, os transformavam em benesses com que atendiam a suas clientelas. 
Dentro desse contexto, a biblioteca pública sempre ficou vulnerável aos mandos e desmandos de seus governantes locais. A maioria dos municípios do país não possui políticas públicas específicas para a área de bibliotecas e $8 \%$ deles não possui sequer uma biblioteca pública (CENSO, 2010).

É interessante perceber que alguns governos locais veem como um diferencial em sua gestão a construção de um prédio para abrigar a biblioteca pública. Em muitos desses casos, a inauguração é usada como fins eleitoreiros, e a biblioteca como espaço de ação fica relegada, tendo os governos subsequentes de lidar com o déficit deixado pelo seu antecessor. Problemas como falta de recurso para manutenção do acervo e infraestrutura, além de salários inadequados, são comuns nos pequenos municípios do interior do país, o que inviabiliza a contratação de bibliotecários com formação para atuar e implementar serviços de qualidade para a população.

São poucos os artigos que tratam especificamente de políticas públicas locais para bibliotecas. Nesse contexto, vale destacar a reflexão apresentada por Ferreira (2006) sobre a realidade das bibliotecas públicas no estado do Maranhão.

São as grandes cidades que, tradicionalmente, se destacam nessa área, por meio de seus Sistemas Estaduais e/ou Municipais de Bibliotecas.

A cidade de São Paulo é um referencial em termos de políticas públicas para bibliotecas, o que não significa que as mesmas sejam suficientes, contínuas ou ainda criadas de maneira participativa. Pelo contrário, não temos exemplos significativos no país de políticas públicas locais para essa área construídas de maneira participativa. $\mathrm{O}$ maior destaque nesse sentido foi aquele liderado por Marilena Chaú quando, no período de 1989 a 1992, à frente da Secretaria Municipal de Cultura de São Paulo, implantou a proposta da Cidadania Cultural, baseada na definição de política da cultura pelo prisma democrático. Naquele momento foi criado o projeto Biblioteca do Cidadão, que dava "ênfase na biblioteca como espaço específico de leitura, informação e pesquisa, considerando suportes complementares outras atividades como teatro e música" (CHAUI, 2006, p. 92). No período de 2001 a 2003, uma nova gestão tentou retomar esse processo, iniciando pela elaboração de um diagnóstico com o objetivo de levantar os problemas e as expectativas tanto da comunidade interna (equipe) como da comunidade externa (usuários reais e potenciais). Os resultados desse diagnóstico evidenciaram, em relação à comunidade interna, a falta de prática em ações 
participativas, a pouca compreensão das equipes das bibliotecas em relação ao seu papel social, cultural e político na sociedade e a falta de sensibilidade para relacionar-se com as comunidades. A partir desses resultados, utilizando métodos pedagógicos de gestão participativa, foi iniciada a construção de um planejamento participativo no então Departamento de Bibliotecas Públicas. No entanto, em função de mudança de direção na Secretaria de Cultura, o processo foi interrompido antes de ser implementado efetivamente. Exemplos como esses são raros e, como podemos perceber, se não conseguirem atingir um nível de apropriação por parte dos funcionários e da sociedade como um todo, são facilmente interrompidos.

\section{Considerações finais}

A partir desse breve panorama podemos identificar mudanças significativas no nível federal, seja em relação à ampliação da participação da sociedade na elaboração de políticas públicas para as bibliotecas, seja no investimento de recursos para construção e modernização de prédios para as mesmas, ou ainda na sistematização de dados que geraram os últimos documentos publicados pelo IBGE e pela FGV.

No entanto, a partir desse mesmo panorama é possível perceber também alguns pontos críticos nesse processo, tal como a desigualdade de poder e capacidade de influência entre os diferentes atores no processo de participação; a sobreposição que há entre algumas instituições, tal como o PNLL e o SNBP; o investimento em Pontos de Leitura deslocados das Bibliotecas Públicas; a inexistência de um plano de avaliação dos impactos dos investimentos previstos no Programa Mais Cultura; e, o que consideramos o mais grave: a falta de atenção para a formação de equipes capacitadas para atuar nesses espaços.

Em relação às políticas locais, a situação é mais grave pois os governos dos estados e dos municípios, de modo geral, não estão preocupados com a biblioteca pública e não as veem como espaços estratégicos para o desenvolvimento local.

Se quisermos instalar processos de elaboração de políticas públicas transparentes, que interfiram positivamente na triste realidade apresentada pelo primeiro Censo de Bibliotecas Públicas, precisaremos aprofundar nossos estudos e lançar mão de metodologias que nos ajudem a explicar as causa e consequências de determinadas 
ações governamentais. Avançar nessa área nos ajudará a entender melhor as relações entre Estado, política e sociedade.

\section{Referências}

BIBLIOTECA NACIONAL (Brasil). Sistema Nacional de Bibliotecas Públicas: Histórico. Rio de Janeiro, 2006. Disponível em:<http://www.bn.br/snbp/historico.html> Acesso em: 14 jan. 2010.

BRASIL. Ministério da Cultura. Editais: Ministério da Cultura. Disponível em: $<$ http://www.cultura.gov.br/site/categoria/editais-ministerio-da-cultura/>. Acesso em: 21 jun. 2010.

BRASIL. Ministério da Cultura. Por que aprovar o Plano Nacional de Cultura: conceitos, participação e expectativas. Brasília: MINC, 2009.

BRASIL. Ministério da Cultura. Pontos de cultura. Brasília: Ministério da Cultura, [2007?]. Disponível em: < http://www.cultura.gov.br/cultura_viva/?page_id=31> Acesso em: 21 jun. 2010.

BRASIL. Decreto $n^{\circ}$ 6.226, de 4 de outubro de 2007. Institui o Programa Mais Cultura. Diário Oficial [da] República Federativa do Brasil, Poder Executivo, Brasília, DF, 5 out. 2007a. Disponível em: <http://www.planalto.gov.br/ccivil_03/_Ato2007 2010/2007/Decreto/D6226.htm>. Acesso em: 21 jun. 2010.

BRASIL. Ministério da Cultura. Apresentação do Programa Mais Cultura. Brasília: Ministério da Cultura, 2007b. Disponível em:

$<$ http://www.cultura.gov.br/site/2009/02/13/mais-cultura-para-o-brasil-e-o-povo brasileiro-5/>. Acesso em: 22 jun. 2010.

CALABRE, Lia. Políticas culturais no Brasil: balanço e perspectivas. In: Encontro de Estudos Multidisciplinares em Cultura, 3., 2007, Salvador. Anais eletrônicos...

Disponível em: <http://www.gestaocultural.org.br/pdf/Lia\%20

$\% 20$ Pol\%C3\%ADticas\%20Culturais\%20no\%20Brasil\%20balan\%C3\%A7o\%20e\%20 perspectivas.pdf>. Acesso em: 21 jun. 2010.

CENSO Nacional de Bibliotecas Públicas: estudo quantitativo: principais resultados. Brasília: FGV, 2010. Disponível em: <http://www.cultura.gov.br/site/wp content/uploads/2010/05/microsoft-powerpoint-fgv-ap-minc-completa79.pdf $>$. Acesso em: 21 jun. 2010.

CHAUÍ, Marilena de Souza. Cidadania cultural: o direito à cultura. São Paulo: Fundação Perseu Abramo, 2006. 
COELHO NETO, José Teixeira. Dicionário crítico de política cultural: cultura e imaginário. 3.ed. São Paulo : Iluminuras, 2004.

COSTA, Greiner; DAGNINO, Renato (Org.). Gestão estratégica em políticas públicas. Rio de Janeiro: T. Mais.Oito, 2008.

ANUÁRIO de Estatísticas Culturais. Cultura em números 2009. Brasília: MinC, 2009.

FERREIRA, Maria Mary. Políticas públicas de informação e políticas culturais: e as bibliotecas públicas para onde vão? Transinformação, Campinas, v. 18, n.2, p.113-2, maio/ago., 2006.

LINDOSO, Felipe. O Brasil pode ser um país de leitores? : Política para a cultura/política para o livro. São Paulo: Summus, 2004.

MEDEIROS, Jotabê. Pacote para encarar "hipocrisia fiscal". O Estado de S. Paulo, São Paulo, 18 jun. 2008. Disponível em: http://www.cultura.gov.br/site/2008/06/19/pacote-para-encarar-hipocrisia-fiscal/ Acesso em: 15 jul. 2008.

MORIN, Edgar. A cabeça bem-feita: repensar a reforma, reformar o pensamento. 10. ed. Rio de Janeiro: Bertrand Brasil, 2002.

OLIVEIRA, Francisco de. Privatização do público, destituição da fala e anulação da política: o totalitarismo neoliberal. In: OLIVERIA, Francisco; PAOLI, Maria Célia (Org.). Os sentidos da democracia: políticas do dissenso e hegemonia global. Petrópolis: Vozes, 1999. p. 55-82.

PAIVA, Marília de Abreu Martins de. Bibliotecas públicas: políticas do Estado Brasileiro de 1990 a 2006. 2008. 144f. Dissertação (Mestrado em Ciência da Informação) - Escola de Ciência da Informação, Universidade Federal de Minas Gerais, Belo Horizonte, 2008.

PLANO NACIONAL DO LIVRO E LEITURA. Objetivos e metas. Brasília: PNLL, 2006. Disponível em: <http://www.pnll.gov.br/>. Acesso em: 30 jan. 2007.

ROSA, Flávia Goullart Mota Garcia; ODDONE, Nanci. Políticas públicas para o livro, leitura e biblioteca. Ciência da Informação, Brasília, v. 35, n.3, p. 183-93, set./dez. 2006.

TAKAHASHI, Tadao (Org.) Sociedade da informação no Brasil: livro verde. Brasília: Ministério da Ciência e Tecnologia, 2000. 
UNESCO. Marco estratégico para a UNESCO no Brasil. Brasília: UNESCO, 2006.

Disponível em <http://unesdoc.unesco.org/images/0014/001475/147544por.pdf $>$

Acesso em: 31 jan. 2008.

InCID: R. Ci. Inf. e Doc., Ribeirão Preto, v. 1, n.1, p. 94-111, 2010. 